\title{
The Equi-Biaxial Fatigue Characteristics of EPDM under True (Cauchy) Stress Control Conditions
}

\author{
Mark Johnson \\ Technological University Dublin, mark.johnson@tudublin.ie \\ Ray Ekins \\ Technological University Dublin, ray.ekins@tudublin.ie \\ Niall Murphy \\ Technological University Dublin, niall.murphy@tudublin.ie
}

See next page for additional authors

Follow this and additional works at: https://arrow.tudublin.ie/engschmanconn

Part of the Materials Science and Engineering Commons, and the Mechanics of Materials Commons

\begin{abstract}
Recommended Citation
Johnson, M., Ekins, R., Murphy, N., Jerrams, S., Hanley, J. : The Equi-Biaxial Fatigue Characteristics of EPDM under True (Cauchy) Stress Control Conditions, ECCMR (VIII), San Sebastian, Spain, June, 2013.
\end{abstract}

This Conference Paper is brought to you for free and open access by the School of Manufacturing and Design Engineering at ARROW@TU Dublin. It has been accepted for inclusion in Conference Papers by an authorized administrator of ARROW@TU Dublin. For more information, please contact arrow.admin@tudublin.ie, aisling.coyne@tudublin.ie, gerard.connolly@tudublin.ie. 


\section{Authors}

Mark Johnson, Ray Ekins, Niall Murphy, Stephen Jerrams, and John Hanley

This conference paper is available at ARROW@TU Dublin: https://arrow.tudublin.ie/engschmanconn/33 


\title{
The Equi-Biaxial Fatigue Characteristics of EPDM under True (Cauchy) Stress Control Conditions
}

\author{
M. Johnson, J. Hanley \& S. Jerrams \\ Centre for Elastomer Research, Dublin Institute Technology, Republic of Ireland
}

\author{
R. Ekins \& N. Murphy
}

School of Manufacturing \& Design, Dublin Institute Technology, Republic of Ireland

\begin{abstract}
Strain amplitude control is most often employed when carrying out fatigue testing of rubber components. Often the design engineer requires fatigue test data that is based on load amplitude control. This is analogous to engineering or nominal stress amplitude control. This usually makes it easy to maintain the load within the specified test limits during extended testing. Values of true stress and strain can be obtained from this approach, but the magnitudes of the maximum true stresses in these tests increase with accumulated cycles, whereas the equivalent maximum engineering stress values remain constant. This is easily demonstrated in the uniaxial case; however the nature of the applied load in equi-biaxial testing adds complexity. The effect in the equi-biaxial case is amplified as the principal stretch ratios have a more pronounced influence on both true stress and strain than in the uniaxial case. Engineering stress-strain data is particularly useful when representing the fatigue behaviour of elastic materials; however it does not represent reality in the case of rubber samples subjected to repeated high strains. True stress control testing can provide data to verify viscoelastic models used to describe elastomeric behaviour under bi-axial fatigue conditions. A test programme has been devised to examine the effect on fatigue life and stress strain relationships of a material tested under conditions of maximum biaxial true stress. This paper compares the difference in fatigue test predictions when using engineering stress and true stress amplitudes as the control parameters. The Experiments are in the form of equi-biaxial bubble inflation fatigue tests employing the DYNAMET system as described in previous CER publications.
\end{abstract}

\section{INTRODUCTION}

Load amplitude control, analogous to engineering or nominal stress control is a method often employed when carrying out both uniaxial and biaxial testing on rubber components. This method generally allows the load to be maintained easily within specific test limits throughout the duration of a fatigue test. However engineering stress does not accurately represent the behaviour of viscoelastic materials under load. Conversely, true (Cauchy) stress does accurately represent their behaviour under load since its use acknowledges the large change in the deformed area of test samples. Despite this, using true stress as a control for fatigue testing is little used. Part of the reason for this is the complexity in successfully maintaining constant true stress amplitude limits throughout a fatigue test along with the fact that engineering stress control is the norm in industry. When the viscoelastic behaviour of rubber is represented in engineering stress terms "the underlying material effects governing rubber mechanical behaviour are overlooked" (Charlton and Yang, 1994). To achieve constant true stress amplitude control the stretch ratio and the applied load acting on a sample must be monitored in real-time hence the maximum applied load is continuously adjusted to compensate for the changes in cross sectional area.

In service rubber components are subjected to complex loading conditions. Uniaxial load test data is therefore often unrepresentative of actual component behaviour. In order to obtain more accurate fatigue life predictions for elastomers in complex loading conditions, biaxial testing methods are necessary.

Current biaxial tests machines, such as stretch frames, provide a simple biaxial test method. While stretch frames are particularly suitable for low stretch ratio tests, difficulties can arise where high stress ratios or high cycle fatigue tests are required, due to failure of the samples at the clamps rather 
than in the gauge area (Charlton and Yang, 1994). If a requirement for true stress control is also considered, stretch frames become impractical for biaxial fatigue testing.

Bubble inflation is ideal for carrying out equibiaxial fatigue tests with large stretch ratios and where large numbers of cycles are anticipated (Murphy et al. 2003).

While methods of true stress control are problematic during fatigue tests (Mars et al. 2002), utilizing bubble inflation with the implementation of real time stretch ratio feedback control using charged couple device (CCD) cameras enables true stress fatigue control to be achieved (Dynamet system, Murphy et al, 2011).

True (Cauchy) stress is extensively used in FEA calculations, but is normally inferred from engineering test data. The availability of direct true stress control fatigue data allows the verification of modelled outputs based on true stress fatigue predictions.

This paper presents results using true and engineering stress control to allow comparison of fatigue tests carried out in each case. As well as being considered as a fundamental requirement of dynamic testing of rubber, the comparison was undertaken to establish if using constant true (Cauchy) stress amplitude as a control parameter for fatigue tests may lend itself to using the maximum principle Cauchy (true) stress as a fatigue life predictor. Doing so may also lead to a decrease in the number of tests required to obtain a credible value for the fatigue strength of a material. (Flamm et al, 2003)

\section{BACKGROUND}

The Dynamet system, previously reported (Murphy et al, 2009, 2011), a test system which uses the bubble inflation method to subject elastomers to equibiaxial loading. Fatigue tests can be carried out using engineering stress, true stress, stretch ratio, volume or pressure control limits.

When carrying out fatigue tests between defined stress limits, these limits must be specified in either true stress or engineering stress. In the case of biaxial deformation and hence bubble inflation. The relationship between engineering and true stress is:

$\sigma_{\text {eng }}=\left(\sigma_{\text {true }}\right) /(\lambda)$

where $\lambda$ represents the stretch ratio in the direction of the applied load. For the bubble inflation case stress can be expressed as: $\sigma_{\text {eng }}=\mathrm{P}\left(\mathrm{r} / 2 \mathrm{t}_{\mathrm{o}}\right) \cdot \lambda$

and

$\sigma_{\text {true }}=\mathrm{P}(\mathrm{r} / 2 \mathrm{to}) \cdot \lambda^{2}$

where $\mathrm{P}$ is pressure, $\mathrm{r}$ is the radius of curvature of the inflated membrane and $t_{0}$ is the original thickness of the material. (Murphy et al, 2009, Mott et al 2003, Javořik, Dvořàk, 2007)

\section{MATERIAL AND METHODS}

EPDM rubber of 70 Shore A hardness, cross-linked with sulphur and containing low activity carbon black was used in this investigation. The test samples consisted of $50 \mathrm{~mm}$ diameter, $1.6 \mathrm{~mm}$ thick EPDM discs inflated through a $38 \mathrm{~mm}$ orifice using an inflation fluid that would not induce swelling in the test samples (Jerrams et al, 2008).

During testing, samples were clamped at their periphery, inflated to a maximum upper stress and deflated to a stress of zero repeatedly until failure occurred.

All samples were preconditioned before testing. Preconditioning was achieved by cycling each samples six times to the maximum stress control limit. After these cycles, each sample was unloaded and the stretch ratio was reset to a value of one. Preconditioning in this way is especially useful in the bubble inflation case as the set caused by the preconditioning cycles eliminates difficulties of initial radius values approaching infinity. Two studies were carried out for the EPDM sample set:

A first set of samples were cyclically loaded to a constant maximum engineering stress until failure occurred.

A second set of samples were cyclically loaded to a constant maximum true (Cauchy) stress until failure occurred. This was achieved by reducing the applied load in a regulated procedure to maintain a constant upper true stress as the stretch ratio increased during accumulated cycles.

\section{RESULTS}

As a basis for comparison, tests were carried out where the material was loaded to an initial true (and engineering) stress, with thereafter one set of samples being maintained at constant true stress for subsequent cycles and the other being subjected to repeated constant engineering stress cycles. The test results shown in figure 1 are for samples subjected to constant true stress control, while figure 2 illustrates the expected reduction in engineering stress values during the test. Similarly, samples subjected 
to engineering stress control displayed increasing levels of true stress with accumulated cycles during testing.

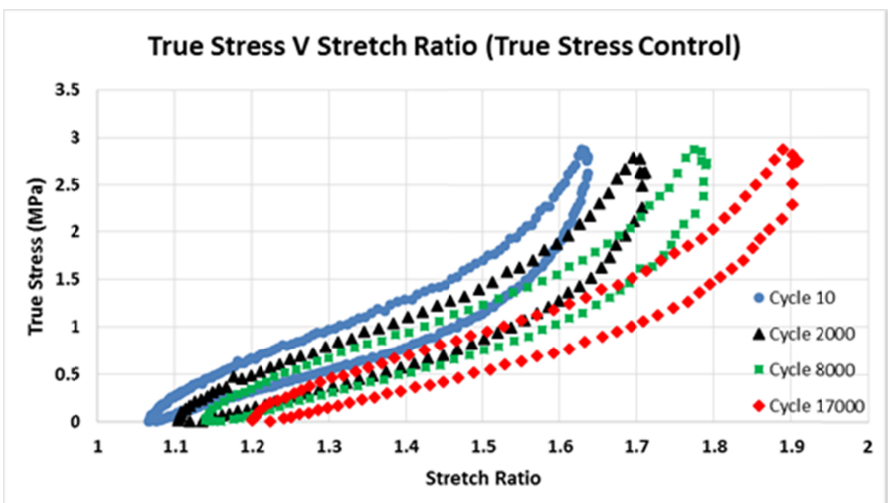

Figure 1. True Stress V Stress Ratio for Various Cycles during a Constant Eng Stress Amplitude Fatigue Test

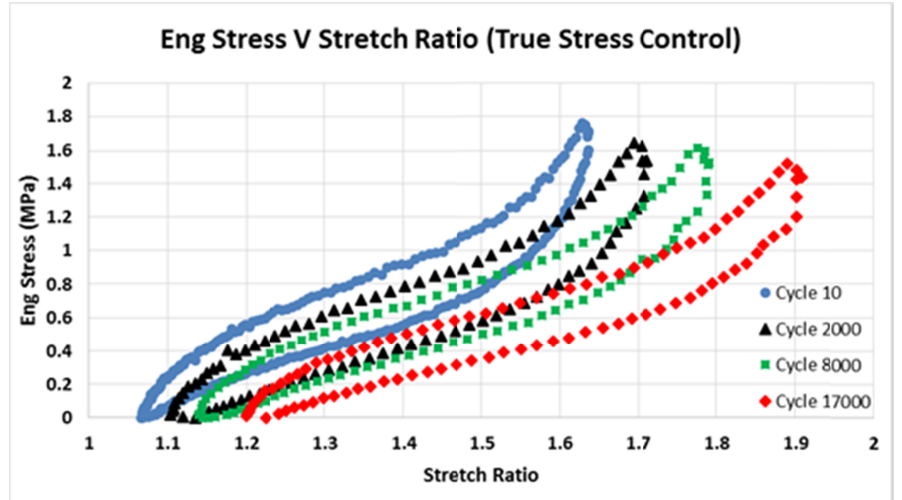

Figure 2. Eng Stress V Stress Ratio for Various Cycles during a Constant Eng Stress Amplitude Fatigue Test

Wöhler curves produced for the two control methods are shown in figure $3 \& 4$.

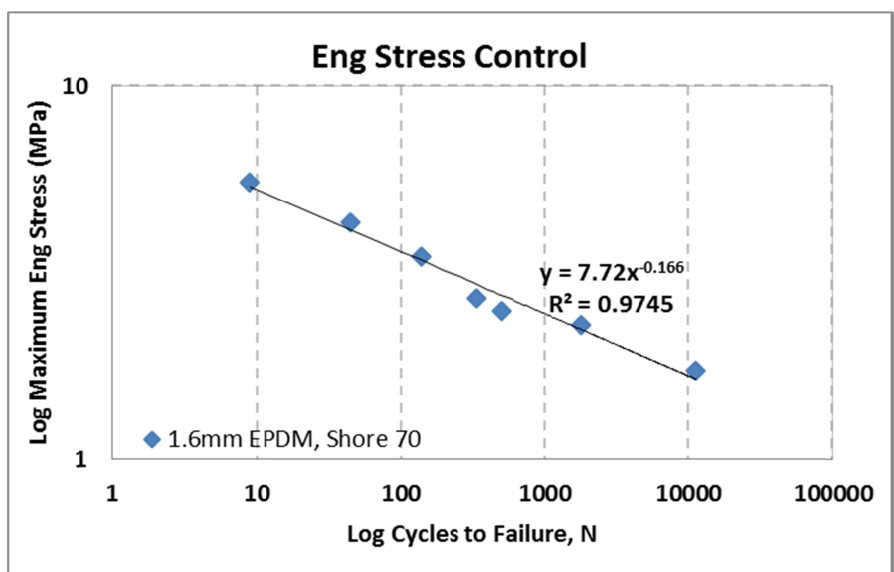

Figure 3. Constant Eng Stress Amplitude Control Wöhler Curve Fatigue Results

Taking one example from the data given in the Wöhler curves, it can be shown that in a fatigue test with an initial stress amplitude of $2.5 \mathrm{MPa}(4.2 \mathrm{MPa}$ true stress equivalent) which is subsequently cycled at constant engineering stress, a fatigue life of 479 cycles was obtained. A similar sample subjected to constant true stress control from the same initial conditions lasted for 1525 cycles. This pattern is repeated throughout the range of fatigue tests shown.

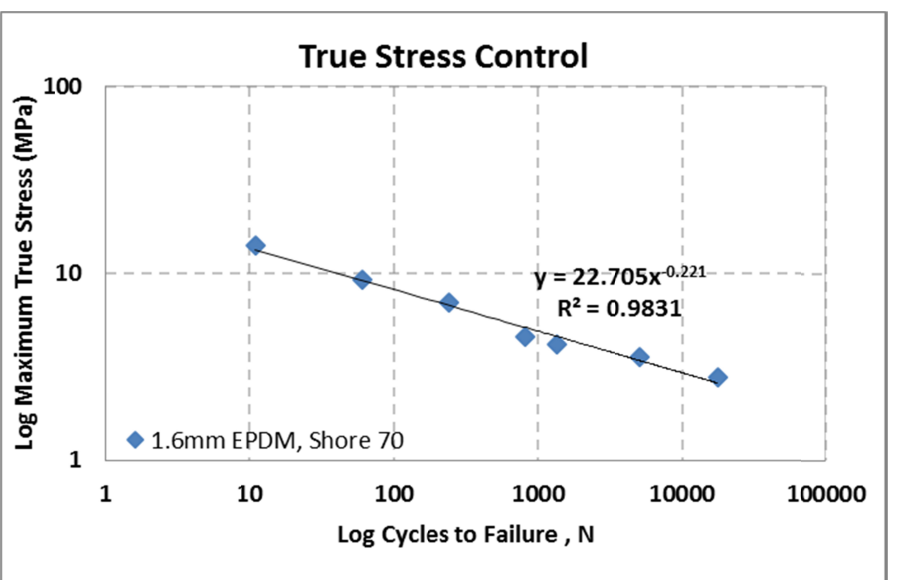

Figure 4. Constant True Stress Amplitude Control Wöhler Curve Fatigue Results

\section{DISCUSION}

The results obtained illustrate that true stress control is possible using the bubble inflation method. These tests show the fatigue lives under engineering stress control, from an initial fixed stress amplitude, are shorter. The true stress values increase throughout the test and thus a direct comparison with true stress control is not valid. A method of making a more valid comparison was investigated whereby the results from the true stress Wöhler curves were compared to a plot of the final true stress values at failure for each engineering stress test plotted against the number of cycles to failure. The results for this approach are shown in figure 5.

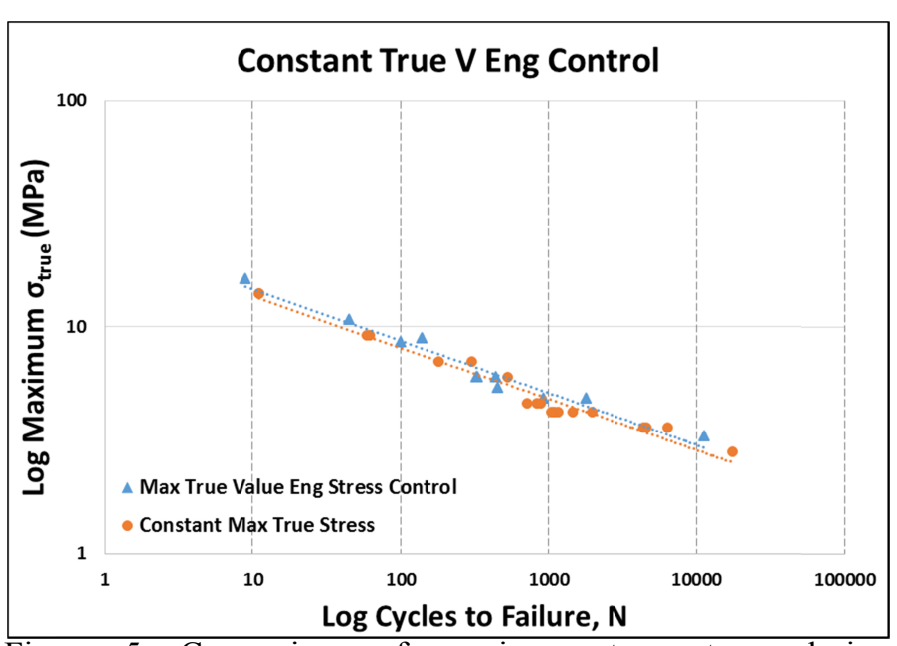

Figure 5. Comparison of maximum true stress during engineering stress control to constant true stress Wöhler curve

This plot appears to show that regardless of whether constant engineering stress control or true 
stress control is employed, the number of cycles obtained during a fatigue test is a function of the maximum true stress applied. This is despite the fact that the loading history in both cases is very different (Mars, et al. 2004).

Hence, it appears that for these materials and the test methods used here, engineering stress control data can be used to produce a satisfactory representation of fatigue behaviour during constant true stress control. However engineering stress control offers no ability to limit the maximum true stress applied to a sample throughout a test. This presents a difficulty if it is required that a certain maximum true stress is not exceeded or if it is stipulated that a failure occurs at a defined true stress value. Engineering stress control is not suitable in this case as the maximum true stress will either not reach or will exceed the desired limit. This is clearly not ideal if true stress is the controlling parameter which is to be investigated. To obtain similar fatigue lives between both methods, a higher value of true stress must be applied in the initial cycle for constant true stress control than that for engineering stress control.

\section{CONCLUSIONS}

Constant true stress amplitude control equi-biaxial fatigue data can be obtained using the bubble inflation method (Dynamet). The fatigue life data obtained in these tests appears to be reliable; however the results can also be reasonably accurately inferred from constant engineering control tests. An advantage of true stress control is that every sample will fail at the specified true stress limit, whereas this is usually only achievable in engineering stress control following extensive trial testing to establish the equivalent engineering failure stress. Both methods appear to be consistent in terms of fatigue prediction despite differing loading histories.

\section{PROPOSED FURTHER WORK}

Further tests are required encompassing a range of materials and stress amplitudes to establish if the results shown here are fully representative of the fatigue resistance of rubber-like materials. A comparison of accumulated dynamic stored energy throughout the test cycles should also be made to determine if the use of the dynamic stored energy criterion as a fatigue predictor for rubber would be appropriate (Alshuth, et al. 2002). Also the test equipment is to be upgraded to record cumulative dynamic stored energy to determine the relationship between values achieved with each control method and their associated fatigue lives.

\section{REFERENCES}

Alshuth, T., Abraham, F., Jerrams, S. 2002 "Parameter Dependence of the Fatigue Properties of Elastomer Products", Rubber Chemistry and Technology, 75, No. 4, pp. 635-642

Charlton, D.J, Yang, J. 1994 "A review of methods to Characterise Rubber Elastic Behaviour for the use in Finite Element Analysis", Rubber Chemistry and Technology, 67, No. 3, pp. 481-503

Flamm, M., Steinweger, T., Weltin, U. 2003 “A method for determining equi-biaxial fatigue in elastomers." 3rd European Conference on Constitutive Models for Rubber (ECCMR), 2003, London, England

Mars, W.V., Fatemi, A. 2002 "A literature survey on fatigue analysis approaches for rubber", International Journal of Fatigue, 24, pp. 949-961

Mars, W.V., Fatemi, A. 2004 "FACTORS THAT AFFECT THE FATIGUE LIFE OF RUBBER: A LITURATURE SURVEY", Rubber Chemistry and Technology, 77, No. 3, pp. 391-412

Murphy, N., Spratt, C., Ronan, S., Jerrams, S., Johannknecht, R. 2003 "A method for determining equi-biaxial fatigue in elastomers." 3rd European Conference on Constitutive Models for Rubber (ECCMR), 2003, London, England

Murphy, N., Hanley, J., Jerrams, S. 2009 "The Effect of PreStressing on the Equi-Biaxial Fatigue Life of EPDM" 6th European Conference on Constitutive Models for Rubber (ECCMR), 2009, Dresden, Germany

Murphy, N., Hanley, J., Jerrams, S. 2011 "The Effect of PreStressing on the Equi-Biaxial Fatigue Life of EPDM" 7th European Conference on Constitutive Models for Rubber (ECCMR), 2011, Dublin, Ireland

Mott, P., Roland, C. M., Hassan, S. 2003 "Strains in an Inflated Rubber Sheet", Rubber Chemistry and Technology, 76, No. 2, pp. 326-333

Javořik, J., Dvořàk, Z. 2007 "Equi-biaxial Test of Elastomers", KGK Kautschuk Gummi Kunststoffe, September 2007, pp.456-459

Jerrams, S., Hanley, J., Murphy, N., Ali, H. 2008 “Equi-Biaxial Fatigue of Elastomers: The Effect of Oil Swelling on Fatigue Life", Rubber Chemistry and Technology Journal, Vol 81, No. 4, pp 638-649 